\title{
LECTURA Y ESCRITURA ACADÉMICAS EN ENTORNOS DIGITALES. OBSTÁCULOS ${ }^{1}$ EPISTEMOLÓGICOS
}

Profesora Elba MEANA ${ }^{(*)}$

Objetivo:

Reflexionar críticamente acerca de las competencias lingüístico- comunicativas involucradas en los procesos de lectura y escritura académicas digitales en el ámbito universitario.

"[es] probable que hoy estemos a las puertas de una nueva revolución educacional. Tanto el entorno en el que opera la escuela como los propios fines de la educación están siendo transformados drástica y rápidamente por fuerzas materiales e intelectuales que se hallan fuera del control de la comunidad educativa pero cuyos efectos sobre esta serán inevitables". ${ }^{2}$

\section{RESUMEN:}

Se abordan los obstáculos de la enseñanza universitaria de la lectura y de la escritura como una episteme. ¿Qué es lo que es necesario de ser enseñado y cómo procede el cerebro cuando se trabaja en contextos analógicos o digitales?

\section{ABSTRACT}

The obstacles to the university teaching of reading and writing as an episteme are addressed. What is necessary to be taught and how does the brain proceed when working in analog or digital contexts?

Habitamos un mundo en que las mayores batallas campales por el poder ya no radican en la materia prima, ni solo tecnológica, ni nuclear; sino en la imposición del significado, y saber detectarlo, analizarlo críticamente, y tener de él una opinión fundada desde la episteme y bien elaborada desde el plano de lo textual, ya sea como oralidad o como escritura, pertinente en cuanto al tema, adecuada desde un contexto analógico, y también, más que nada, y de esto se trata aquí, digital; es, sin dudas, el desafío de esta propuesta.

(*) FACENA. Correo electrónico: eemeana@gmail.com 
Demanda de distribución de conocimiento ${ }^{3}$

Modernidad

Enseñar

a leer y escribir

durante la niñez versus

Sociedad del conocimiento

Aprender

las competencias del siglo XXI

a lo largo de toda la vida
Si como se lee más abajo, se ha reemplazado el concepto de "Modernidad" por el de "Sociedad del conocimiento", CABE PREGUNTARSE:

¿Cuáles de todas las significaciones que tienen la lectura ${ }^{4}$ y la escritura ${ }^{5}$ desde las distintas teorías serán importantes de ser recortadas aquí, cuando se trata de macrohabilidades menos físicas y más mentales, conscientes ${ }^{6}$, menos lineales y más abiertas, circulares, intertextuales, y con recursos más autodirigidos, como lo son las TIC?, ¿ y qué rasgos específicos asumen estas dos competencias lingüísticas básicas, cuando se trata de describirlas, situadas como están en un contexto de producción y recepción todavía más singular como lo es el campo de la comunicación académica?

¿Qué implicaciones pedagógicas tendrá el salto de unas herramientas analógicas a otras digitales? Y a la universidad, en especial, ¿qué le espera?, ¿qué caminos deberá adoptar para adaptarse a este nuevo paradigma?

Esta temática tiene como base a un profesional reflexivo, en términos de Schön $(1998)^{7}$,que, haciendouso de su "racionalidad interpretativa", construye para sus alumnos consignas que le permitan acortar la brecha digital en la generación del conocimiento, fundado en la aceptación de la incertidumbre y la complejidad, a diferencia del simple procesamiento de la información, típicamente analógico, que se funda en la certeza.

Así, las fronteras se ensanchan, se desdibujan: habrá que pensar en nuevos formatos y dispositivos, en consignas acordes con la virtualidad, que no es la no presencia, ni tampoco la transformación de una realidad en un conjunto de posibles, sino la redistribución de los objetos de estudio, sus inevitablemente diferentes formas de abordaje, que sitúan la clase en espacios y tiempos diferentes.

Estos tiempos y espacios nuevos, requieren pensar al lenguaje ${ }^{8}$ digital no como texto virtual en el sentido tradicional del enunciado sino como un acto permanente de creación, de construcción infinita de múltiples inter e hipertextos, allí donde leer y escribir supone, como este trabajo propone, el manejo certero de nuevas lógicas de organización de la información y de gestión del conocimiento.

No es una lógica de subordinación a lo tecnológico, tampoco de dominación, sino de negociación con la cultura de la tecnología puesta al servicio de un aprendizaje que se impone necesariamente diferente: 
pasar de la monoculturalidad a la diversidad, del acceso limitado al ilimitado, de una interacción diferida a una simultánea, y también donde los sintagmas y nuevos géneros discursivos posibilitan una mayor descarga cognitiva (a diferencia de los textos analógicos), posibilitando procesos de composición y descomposición semánticos menos lentos y más eficaces. Naturalmente que estas nuevas miradas requieren de un docente cada vez más profesional, abierto, y flexible a estas modalidades.

Pensar, leer y escribir: ¿cómo sería entonces esa "linealidad" del "entorno digital”?, ¿qué papel le cabría en tal caso al lector como constructor de significados"?, ¿qué habilidades "otras" debería poseer este tipo de lector?, ¿cómo reconstruir la idea de linealidad si se piensa que el soporte digital lo rompe definitivamente?

Estas preguntas requieren ejercitar en los alumnos el pensamiento divergente y desarrollar en ellos las habilidades cognitivas y lingüísticas para transformar (sin repetir), ideas con precisión y claridad; para construir nuevos conocimientos en el manejo de situaciones de lectura y escritura que necesariamente deberán ser nuevas/diferentes de las convencionales, y para lo cual es indispensable que las consignas también estén adecuadas a esta nueva manera de aprender: web quest, escrituras colaborativas, búsqueda de datos o sugerencia de bibliografía digital para informar (en el aula virtual, o con el uso de celulares, preparación de power point) en clase o exámenes, revisión y versión final de textos. ¿Qué criterios tener en cuenta?
1) Reemplazar la instrucción lineal por la experimentación, resolución y construcción del saber, incluyendo errores.

2) Dejar de lado la imposición heterónoma con obediencia por la autonomía responsable y consensuada.

3) Sustituir el refuerzo de la repetición por la percepción situada, que busca sentido y comprensión, memoria útil, e involucramiento. ${ }^{9}$

Estos criterios se podrán poner en acción trabajando de cerca con los alumnos el desarrollo de sus "competencias", desde una perspectiva holística del enunciado; "competencias", que en la práctica pedagógica de la enseñanza ha configurado hasta ahora una mirada reduccionista en términos de Hayland (1994), un punto de vista atomizado, rígido y lineal, al entenderlas como comportamientos observables y sin relación con atributos mentales y construcciones sociales provisorias. El enfoque tradicional de las Competencias Lingüísticas ignora la conexión compleja e interactiva entre tareas, los atributos mentales que subyacen a los comportamientos de los significados, las intenciones, las disposiciones, el poderoso influjo que ejerce la cultura como medio de construcción de la realidad.

La OCDE (Organización para la Cooperación y el Desarrollo Económico) ha difundido en el año 2.003 su versión definitiva de la acepción "COMPETENCIAS".

Uno de los documentos básicos de estas revisiones es el denominado De Se Co (Definición y Selección de Competencias). Según este documento las COMPETENCIAS deberían definirse dentro de tres am- 
plias categorías consideradas prioritarias para el desarrollo de los estudiantes de todo el continente, a saber:

* a) Poder usar un alto rango de herramientas para poder interactuar en los distintos ámbitos.

* b) Poder comunicarse con otros y en grupos heterogéneos

* c) Actuar de manera autónoma y tomar responsabilidades para manejar sus propias vidas.

Por todo ello la idea de COMPETENCIA está asociada actualmente a las capacidades y destrezas para la gestión más eficiente de la economía del conocimiento, asociada a la inteligencia emocional, y la tramitación adecuada de la actitud, rasgo este bastante descuidado en los claustros de todos los niveles en estos últimos años.

Por tanto, el alumno no sólo necesita ejercitar las estrategias cognitivas y lingüísticas propias de la lectura y de la escritura, los componentes textuales de coherencia y cohesión, el mecanismo de las macrorreglas, la importancia del Tema y el Rema en la construcción de la Progresión Temática, el valor del reconocimiento de las tipologías textuales (tanto en su comprensión como en su producción), sobre todo las atinentes al razonamiento ${ }^{10}$. Asimismo, es fundamental aprender a montar y desmontar los textos, que les permitan leer entre líneas los metalenguajes socialmente construidos e históricamente acumulados, así como su ideología, y la gestión inteligente de las respuestas más adecuadas a cada situación comunicativa; lo que implica considerar el nivel de lengua correspondiente, de acuerdo con el tipo de enunciatario, e intencionalidad, lo que habrá de producir un tipo determinado de texto y de género discursivo.

Por otra parte, se sabe que los estudiantes universitarios tienen dificultades no sólo en el plano de la oralidad secundaria, sino también en el plano de los textos escritos, tanto en el ámbito de la lectura, como así también de la escritura. Los alumnos no están familiarizados con esas nuevas formas discursivas propias de "culturas escritas", en términos de Lynda Flowers ${ }^{11}$, que ellos no manejan provisoriamente, y se transforman por tanto en barreras insalvables de su formación académica. Leer (comprender) implica poner en escena unos saberes previos, una razón por la cual leer, unos andamiajes, en términos de Bruner ${ }^{12}$, que el alumno deberá ejercitar en forma conjunta con el docente y con sus compañeros. No es verdad que los alumnos no sepan leer comprensivamente; ocurre que no están debidamente estimulados, orientados, muchas veces desconocen los contextos de situación en que esos textos han sido elaborados. Así también, el desconocimiento del léxico, la lectura entrecortada que realizan los propios alumnos es razón de incomprensión.

Se hace necesario concluir con algunas sugerencias básicas vinculadas con esta temática, y tiene que ver con el hecho de proponer la lectura conjunta en todo tipo de formatos tecnológicos, siempre acompañados por el docente, con especificación concreta, a partir de consignas orientadoras y autogestionarias del por qué y para qué leer, el reconocimiento de las estrategias que llevan adelante los lectores expertos (notas 
al margen, subrayado, relectura, estrategia skim (vistazo) y scan (atenta), consulta a otros textos, enlaces, hipertextos, imágenes, audios, protocolos de lectura, mapas semánticos, cuadros sinópticos, esquemas, dibujos, imágenes, fórmulas.

Es importante también recordar que la escritura, asimismo, implica construir un puente entre el conocimiento viejo y el nuevo, que exige poner en relación lo que uno ya sabe con lo que demanda la actual situación de escritura, construir el PROPIO CONTEXTO comunicativo, detectar el problema retórico: posicionarse como enunciadores; y los estudiantes universitarios no siempre están preparados para ello, porque no usan la escritura epistémicamente: solo están habituados a modificar algunas frases, y les resulta complejo el uso de sus ideas propias: son "peligrosas" porque el manejo del discurso científico requiere de un conocimiento sólido, de unas estructuras de pensamiento y un entrenamiento retórico al que el estudiante está poco habituado.

Y para finalizar: Desde las diferentes carreras universitarias, en su conjunto, no se debería evaluar solamente cuánto el alumno sabe de un tema, sino también: cómo lo expresa, habría que tener en cuenta la ejercitación retórica, a partir de restricciones que operan como impulso para la redacción pensada en términos de una audiencia concreta, de una finalidad específica, de una forma de coherencia y cohesión, y de una estructura que deberán, todas ellas estar debidamente coordinadas. Ejercicios del tipo de, por ejemplo: producir un género distinto o pensar en unos destinatarios diferentes; así como también revisar los textos escritos en razón de criterios previamente acordados, redactar guiones para una exposición oral, escribir colaborativamente en el aula virtual, participar de foros de discusión, haciendo uso de formatos textuales específicos: textos expositivos explicativos, argumentativos, informes de experimentos, de bibliografía específica propuesta desde el aula virtual.

De este modo los textos a ser leídos o escritos se verán configurados por una perspectiva, en que las Competencias Lingüísticas adquieren una vital finalidad instrumental, ya que es a través de los procedimientos retóricos como se da paso a los conceptos o tematización de contenidos en cualquier campo del saber. 


\section{REFERENCIAS:}

1. Un obstáculo es una concepción que ha sido en principio eficiente para resolver algún tipo de problemas pero que falla cuando se aplica a otro. Debido a su éxito previo se resiste a ser modificado o a ser rechazado: viene a ser una barrera para un aprendizaje posterior. Se revela por medio de los errores específicos que son constantes y resistentes. Para superar tales obstáculos se precisan situaciones didácticas diseñadas para hacer a los alumnos conscientes de la necesidad de cambiar sus concepciones y para ayudarlos a conseguirlo.

Brousseau (1983) da las siguientes características de los obstáculos:

- un obstáculo es un conocimiento, no una falta de conocimiento;

- el alumno utiliza este conocimiento para producir respuestas adaptadas en un cierto contexto que encuentra con frecuencia;

- cuando se usa este conocimiento fuera de este contexto genera respuestas incorrectas. Una respuesta universal exigiría un punto de vista diferente;

- el alumno resiste a las contradicciones que el obstáculo le produce y al establecimiento de un conocimiento mejor. Es indispensable identificarlo e incorporar su rechazo en el nuevo saber;

- después de haber notado su inexactitud, continúa manifestándolo, de forma esporádica.

Se distinguen los siguientes tipos de obstáculos:

- OBSTÁCULOS ONTOGENÉTICOS -a veces llamados obstáculos psicogenéticos: se deben a las características del desarrollo del alumno.
- OBSTÁCULOS DIDÁCTICOS: que resultan de las elecciones didácticas hechas para establecer la situación de enseñanza.

- OBSTÁCULOS EPISTEMOLÓGICOS: intrínsecamente relacionados con el propio concepto.

Barrantes, Hugo. (Obstáculos epistemológicos). En "Cuadernos de investigación y formación en Educación Matemática”.2006, Año 1, Número 2.

Recuperado de http://www.unsj.edu.ar/unsjVirtual/diplomatura_educacionNuevasTecnologias/wp-content/uploads/2015/08/ Genesisdelos Obst\%C 3\% A 1 culosEjemploMatem\%C3\%A1tica-1.pdf

2. BRUNER, J.J." (2000). "La Educación al encuentro de las nuevas tecnologías”. Recuperadode: http://200.6.99.248/ bru487cl/ files/JJ_IIPE_BA_4.pdf

3. AGUERRONDO, I. y Denise Vaillant, D. (2015). "El aprendizaje bajo la lupa. Nuevas perspectivas para América Latina y el Caribe" (Septiembre, 2015).

Recuperado de https://www.unicef.org/ lac/UNICEF_Aprendizaje_bajo_la_lupa_ nov2015(1).pdf

4. Según Jean Herbrard el acto de lectura no es un acto natural, según este especialista en historia y sociología de la lectura, las actividades involucradas en ella nacen de la civilización; sostiene que los alumnos no son cultos en ese sentido". Herbrard, J. (2000): "Conferencia a los Formadores de Formadores (FORDECAP), Ministerio de Educación, Ciencia y Tecnología de la Nación”. 
5. Carlino, P. (2005): "La escritura en el Nivel Superior", En: "Escribir, leer y aprender en la Universidad”. Buenos Aires. F.C.E., Cap 1.

6. Y también "inconscientes" que median entre quien enseña y quien aprende, ya que no todo lo que se enseña es aprendido. Sabido es que ambos actores pedagógicos están mediados por el significante, en términos de Lacan; también por el niño que alguna vez fue ese docente, y por las "ilusiones pedagógicas" de las que éste parte, entre otras: la de un saber ya construido (difícil de sistematizar por un alumno que al momento de la explicación carece de los esquemas que puedan facilitar la comprensión de lo que se enseña). Otra ilusión pedagógica es la del "alumno ideal”. Éstas y otras idealizaciones juegan un sustantivo papel en el discurso didáctico, que, sin saberlo conscientemente el docente, inciden notablemente en el acto pedagógico. Este es un aspecto muy escasamente difundido, sobre todo en el Nivel Universitario. C.f.r.: Castorina, J /Lenzi, A. y Fernández, S.(2.000). "Psicogénesis e Ilusiones pedagógicas". En: "Psicología genética y los procesos de aprendizaje”. Bs. As.: Miño y Dávila.

7. Schön, D.A.(1998). El profesional reflexivo”.

Recuperado de

http://www.practicareflexiva.pro/wp-ntent/ uploads/2011/05/D.SCHON_FUNDAMENTOS.pdf

8. Sabemos hoy, gracias a la ciencia, que el uso del lenguaje no puede ser el reflejo de la realidad, es una verdad que forma parte de ella, pero no puede calcarla, solo representarla.
9. FAINHOLC, B. (2004). "Lectura Crítica en Internet. Evaluación y aplicación de sus recursos".

Recuperado de file://C:/Users/STUDIO/ Downloads/Dialnet-LaLecturaCriticaEnInternet-1985806.pdf

10. "Forma, contexto referencia: parámetros para la identificación de discursos de razonamiento" (demostración/argumentación/ explicación). En: Zamudio, B. y Atorresi, A. (2.000). "La explicación”. EUDEBA: Bs As.

11. Briceño Marquez, J. A. (2014). “El modelo de Flower y Hayes : Una estrategia para la enseñanza de la escritura académica”.

Recuperado de http://repository. ut.edu.co/bitstream/001/1150/1/RIUTBHA-spa-2014-E1\%20 modelo\%20 de\%20F1ower \%20y\%20 Hayes. $\% 20$ Una $\% 20$ estrategia $\% 20$ para $\% 201$ a $\% 20$ ense $\%$ C3\%B1anza\%20de\%201a\%20escritura\%20acad\%C3\%A9mica.pdf

Centro Virtual Cervantes. Diccionario de términos clave de ELE. Concepto de andamiaje. (2017)

Recuperado de http://crc.cervantes.es/ensenanza/biblioteca_ele/diccio_ele/diccionario/andamiaje.htm

12. Centro Virtual Cervantes. Diccionario de términos clave de ELE. Concepto de andamiaje. (2017)

Recuperado de http://cvc.cervantes.es/ensenanza/biblioteca_ele/diccio_ele/diccionario/andamiaje.htm 